\title{
Changes in Quality Attributes Related to Browning during Storage of Litchi Juice Fermented by Lactobacillus
}

\author{
Xingxing Yuan ${ }^{1,2}$, Yuanshan $\mathrm{Yu}^{1}$, Yujuan $\mathrm{Xu}^{1}$, Gengsheng Xiao ${ }^{1} \&$ Jijun $\mathrm{Wu}^{1}$ \\ ${ }^{1}$ Sericultural \& Agri-Food Research Institute, Guangdong Academy of Agricultural Sciences/Key Laboratory of \\ Functional Foods, Ministry of Agriculture/Guangdong Key Laboratory of Agricultural Products Processing, \\ Guangzhou, 510610 China \\ ${ }^{2}$ College of Food Science and Engineering, Jiang Xi Agricultural University, Nanchang, 330045 China \\ Correspondence: Yuanshan Yu, Sericultural \& Agri-Food Research Institute, Guangdong Academy of \\ Agricultural Sciences/Key Laboratory of Functional Foods, Ministry of Agriculture/Guangdong Key Laboratory \\ of Agricultural Products Processing, Guangzhou, 510610 China. Tel: 86-159-7559-6649. E-mail: \\ yuyuanshan2016@qq.com
}

Received: April 4, 2019 Accepted: April 19, $2019 \quad$ Online Published: May 22, 2019

doi:10.5539/jfr.v8n4p1 URL: https://doi.org/10.5539/jfr.v8n4p1

\begin{abstract}
Litchi juice fermented by Lactobacillus casei was heated $\left(95^{\circ} \mathrm{C}, 1 \mathrm{~min}\right)$ and stored in a dark place at $25^{\circ} \mathrm{C}$. Changes in quality attributes (color, 5-hydroxymethylfurfural (5-HMF) phenolic compounds, antioxidant capacity, sugars, free amino acids, and others) related to browning in fermented litchi juice were investigated during the six months of storage. Noticeable visual changes due to browning were observed during storage of fermented litchi juice, especially in the upper part of the juice bottle, and the value of color difference $(\triangle E)$ increased to $7.12 \pm 0.04$ after six months of storage. The 5-HMF content increased with the increase in storage time, which rose from 0 to $2.31 \pm 0.16 \mathrm{mg} / \mathrm{L}$ after six months of storage. Five soluble phenolic compounds (rutin, narcissoside, quercetin, kaempferol-rutinose-rhamnoside, and isorhamnetin-rutinose-rhamnoside) were identified in fermented litchi juice, none of which showed a significant decrease $(P>0.05)$, whereas a tendency for total phenolic content to decrease was observed during storage of fermented litchi juice. Adding $0.3 \mathrm{~g} / \mathrm{L}$ of sodium sulfite can inhibit the browning reaction in fermented litchi juice and decrease the formation of 5-HMF as well as the loss of total phenolics.
\end{abstract}

Keywords: fermented litchi juice, pasteurization, browning, 5-HMF, phenolic compounds

\section{Practical Applications}

Non-enzymatic browning is a major factor for quality deterioration during storage of litchi juice. Changes in quality attributes (Color, 5-HMF, phenolic compounds, antioxidant capacity, sugar, free amino acids and so on) related to browning during storage of fermented litchi juice was investigated during 6 months of storage. It was found that adding sodium sulfite can inhibit the browning of fermented litchi juice and the formation of 5-HMF and reduce the loss of total phenolics. Results could provide some data to develop a science-based anti-browning agent for litchi juice.

\section{Introduction}

Litchi (Litchi chinensisSonn.) is cultivated in sub-tropic or tropicregions, in particular south China, Thailand and India (Zhang et al., 2016, Chaikham et al., 2017). With its bright red pericarp, translucent white flesh, exotic flavor, and particular nutritional qualities, litchi has become one of the world's most popular fruits (Holcroft et al., 1996). Apart from being consumed fresh, litchi fruit is also processed into juice, canned litchi, and is dried. Litchi juice typically contains sugar, widely appreciated flavor,minerals, vitamins, and various phenolics, and whichcan compete in the juice market; recently litchi juice, fermented by Lactobacillus, which increases its health benefits with probiotics has emerged on the market (Ibrahim \& Mohamed, 2015). However, non-enzymatic browning is the major cause of quality deterioration during storage of probiotic litchi juice.

It was reported that non-enzymatic browning reactions was brought aboutby maillard-associated reactions, ascorbic acid degradation, and acid-catalyzed sugar degradation. And carbonyl compounds, which is intermediates of ascorbic acid and sugar degradation, can polymerize or react with amino acids and participate in 
maillard-associated reactions to form brown-colored compounds (Buedo, Elustondo, \& Urbicain, 2000, Quayson \& Ayernor, 2007, Damasceno et al., 2008). Color changes, loss of reducing sugar and ascorbic acid, and formation of 5-hydroxymethylfurfural (5-HMF) could be observed, which will affectthe quality of fruit juices and reduced purchase desire of consumers (Ibarz, Pagán, \& Garza, 1999). These undesirable and complex reactions produce a wide variety of end-products, such asfurans, pyrroles, ketones, and other compounds, and can cause off-flavors and bad color (Fustier et al., 2011).

At present, ultrafiltration, concentration, and adding a protective agent have usually been used to avoid non-enzymatic browning, but since the technologies of ultrafiltration and concentration are costly and consume a lot of energy, it is important to seek suitable protective agent for different juice systems (Borneman, Kmen, \& Nijhuis, 2001; Hernández et al., 2009; Fustier et al., 2011; Wu, Hu, \& Zheng, 2014). Browning during storage of juice beverages has already been extensively reported, but there is still a limited understanding to this problem, especially in litchi juice (Ibrahim \& Mohamed, 2015). In this study, changes in quality attributes (color, 5-HMF, phenolic compounds, antioxidant capacity, sugar, free amino acids, and others) related to browning during storage of fermented litchi juice by Lactobacillus were investigated, which could provide some data that could help to develop an anti-browning agent for litchi juice beverage.

\section{Materials and Methods}

\subsection{Preparation of Starter Culture}

Lactobacillus casei(GIM1. 204) preserved in our laboratorywas activated $\left(30{ }^{\circ} \mathrm{Cfor} 12 \mathrm{~h}\right)$ in $\mathrm{MRS}$ broth (HaiboBioTechnology Co. Ltd., Qingdao, China),andthen the cell pellet was used to inoculate litchi juice.

\subsection{Preparation Offermented Litchi Juice}

Litchi juice (cv. Huaizhi) was presented by Guangdong BosunHealth FoodCo. Ltd., Guangzhou, China). After the litchi juicewas incubated at $30{ }^{\circ} \mathrm{C}$ for $18 \mathrm{~h}$ with an initial $5.0 \mathrm{Log} \mathrm{CFU} / \mathrm{mL}$ of Lactobacillus case $i$, the $2 \mathrm{~g} / \mathrm{L}$ of xanthan gum (Shunqi Biotechnology Co. Ltd., China) was also added to the litchi juice for sensory characteristics. Thexanthan gum was dispersed using stirrer and homogenizer, thesamples werepasteurized $\left(105{ }^{\circ} \mathrm{C}, 30 \mathrm{~s}\right)$ in a Laboratory UHT Sterilization Device (Shanghai Pilotech Equipment Co. Ltd., China), and then filled into lipped glass bottle.

\subsection{Storage and Sampling}

The fermented litchi juice in the glass bottle was stored in a dark place at $25{ }^{\circ} \mathrm{C}$ for 6 months and removed at three months interval for further analysis.

\subsection{Color Assessment}

The juice color was measured in the reflectance mode for 3 times at $25^{\circ} \mathrm{C}$ (UltraScan VIS, HunterLab, Reston, America). The $L^{*}, a^{*}$, and $b^{*}$ value was measured and the total color difference $(\Delta E)$ was calculated by Equation 1.

$$
\Delta E=\sqrt{\left(L^{*}-L_{0} *\right)^{2}+\left(a^{*}-a_{0} *\right)^{2}+\left(b^{*}-b_{0} *\right)^{2}}
$$

where $\Delta E$ is the total color difference between a sample and control $(0 \mathrm{~d}$ storage $), L^{*}, a^{*}$, and $b^{*}$ are respectivelythe lightness, redness, and yellowness of a sample, and $L_{0}{ }^{*}, a_{0}{ }^{*}$, and $b_{0}{ }^{*}$ are respectively the lightness, redness, and yellowness of control (samples for $0 \mathrm{~d}$ storage).

\subsection{Determination of Ph, Total Soluble Solids (TSS), and Titratable Acidity}

The $\mathrm{pH}$ of juice samples was measured using a $\mathrm{pH}$ meter (Metrohm744, Herisau, Netherland) at $25 \pm 1{ }^{\circ} \mathrm{C}$. A digital refractometer (Model RP-101, Atago, Co., Ltd., Tokyo, Japan) was used to measure the TSS. The automatic titrimeter (Metrohm Co. Ltd.) was used to analyze the titratable acidity, and the results were expressed as $\mathrm{g}$ citric acid equivalents per liter.

\subsection{Determination of Ascorbic Acid and 5-HMF}

The ascorbic acid was measured according to the methods of Yu et al. (2014) using the HPLC system (Shimadzu Co., Japan).

The 5-HMF was analyzed by HPLC method. The juice sample was mixed with methanol at the ratio of $1: 1(\mathrm{v} / \mathrm{v})$, then centrifuged for $5 \mathrm{~min}$ to collect supernatant with $10000 \times g$ at $4^{\circ} \mathrm{C}$. The supernatant filtered using $0.22 \mu \mathrm{m}$ of nitrocellulose membrane (Beijing Bomex Co., Beijing, China) was then used for further HPLC analysis. The 5-HMF was separated using Agilent ZORBAX SB- Aq $(4.6 * 250 \mathrm{~mm})$ column at $30{ }^{\circ} \mathrm{Cusing} 50 \%(\mathrm{v} / \mathrm{v})$ 
acetonitrile aqueous solution as the elution at a flow rate $1.0 \mathrm{~mol} / \mathrm{L}$ and quantified using external standards with a UV-VIS detector at $280 \mathrm{~nm}$.

\subsection{Determination of Sugar, Total Polyphenols, and Antioxidant Capacity}

Sugars (fructose, glucose, and sucrose) were analyzed using HPLC according to the methods of Yu et al. (2015). Total polyphenols were determined using the Folin-Ciocalteu method (Yu et al., 2014; Aydin et al. 2017). The antioxidant capacity of juice sample was determined by oxygen radical absorbance capacity (ORAC). The ORAC assay refer to the methods of Ou et al. (2001) and Yu et al. (2014), and the result was expressed as mM Trolox equivalent (TE)/L.

\subsection{HPLC Analysis of Phenolic Compounds}

The juice sample was mixed with absolute ethanol using a ratio of $1: 2(\mathrm{v} / \mathrm{v})$ and sonicated with a $200 \mathrm{~W}$ ultrasound power at $40 \mathrm{KHz}$ for $20 \mathrm{~min}$ at room temperature. Subsequently, the mixture was centrifuged at $10,000 \mathrm{rpm}$ for 10 minto collect the supernatant, and then the supernatant passed through a $0.22 \mu \mathrm{m}$ nitrocellulose membrane (Beijing Bomex Co., Beijing, China) were used for further HPLC analysis.An Agilent 1200 RRLC system coupled with Agilent6530 TOF-MS was used. Sample was separated in an Agilent Poroshell 120 EC-C18 column $(3.0 \times 50 \mathrm{~mm}, 2.7 \mu \mathrm{m})$ using the mobile phase consisted of (A) $0.4 \%(\mathrm{v} / \mathrm{v})$ acetic acid and (B) according the methods of Yang et al. (2017). The identification of phenolic compounds was determined by using authentic standards and by comparing itsfragmentation pattern of deprotonated and product ions, while quantification was performed by external calibration with standards of phenolic compounds.

\subsection{Determination of Free Amino Acids}

The free amino acids compositions of litchi juice samples were measured according to the methods of Yu et al. (2015) using amino acids analyzer (Hitachi Ltd., Japan).

\subsection{Statistical Analysis}

Duncan's multiple range tests were used to determine statistically significant differences of variables at $95 \%$ confidence. One-way analysis of variance was accomplished with the software SPSS Statistics 19.0 (IBM Co., USA).

\section{Results and Discussion}

\subsection{Changes in TSS, pH, Titratable Acidity, Ascorbic Acid, Andsugar}

The TSS, $\mathrm{pH}$, and titratable acidity of fermented litchi juice were $15.82 \pm 0.16^{\circ}$ Brix, $4.53 \pm 0.14$, and $2.00 \pm 0.06 \mathrm{~g}$ of citricacid per $1 \mathrm{~L}$, respectively (Table 1). During storage of 6 months, no significant changes $(P>0.05)$ for the TSS, $\mathrm{pH}$, titratable acidity of fermented litchi juice was observed, which may related to the inactivation of indigenous microorganism during thermal pasteurization of fermentation litchi juice. The glucose and fructose were the dominant sugars in fermentation litchi juice, reaching $71.32 \pm 1.04$, and $66.23 \pm 1.12$, respectively (Table 1). No sucrose and ascorbic acid was detected in fermentation litchi juice. It had been reported that sucrose could be hydrolyzed into fructose and glucose during fermentation of $L$. casei (Zheng et al., 2014). Reports had shown that $230 \mathrm{mg} / \mathrm{Lof}$ ascorbic acid was detected in the fresh litchi juice (Zheng et al., 2014), while ascorbic acid was not detected in the pasteurized fermentation litchi juice, which could be attributed to aerobical and anaerobical degradation of ascorbic acid during litchi juice processing and storage (Kennedy et al., 1992; Kabasakaliset al., 2000).

Table 1. Changes in total soluble solids (TSS, ${ }^{\circ}$ Brix), $\mathrm{pH}$, titratable acidity (TA, g/L), sugar (g/L), and 5-HMF $(\mathrm{mg} / \mathrm{L})$ in fermented litchi juice during storage

\begin{tabular}{llll}
\hline Storage times & 0 day & 3 months & 6 months \\
\hline TSS & $15.82 \pm 0.16^{\mathrm{a}}$ & $16.06 \pm 0.12^{\mathrm{a}}$ & $15.93 \pm 0.18^{\mathrm{a}}$ \\
pH & $4.53 \pm 0.14^{\mathrm{a}}$ & $4.36 \pm 0.13^{\mathrm{a}}$ & $4.30 \pm 0.11^{\mathrm{a}}$ \\
Titratable acidity & $2.00 \pm 0.06^{\mathrm{a}}$ & $2.02 \pm 0.02^{\mathrm{a}}$ & $2.02 \pm 0.01^{\mathrm{a}}$ \\
fructose & $66.23 \pm 1.12^{\mathrm{c}}$ & $76.35 \pm 1.53^{\mathrm{a}}$ & $70.45 \pm 1.34^{\mathrm{b}}$ \\
glucose & $71.32 \pm 1.04^{\mathrm{c}}$ & $79.66 \pm 1.28^{\mathrm{a}}$ & $74.74 \pm 1.33^{\mathrm{b}}$ \\
5-HMF & N. D. $^{\mathrm{a}}$ & $0.95 \pm 0.07^{\mathrm{b}}$ & $2.31 \pm 0.16^{\mathrm{a}}$ \\
\hline
\end{tabular}

N.D., Contents below the detection limit. The detection limit of 5-HMF was $0.02 \mathrm{mg} / \mathrm{L}$.

${ }^{\mathrm{a}, \mathrm{b}, \mathrm{c}}$ Different letters represent a significant difference within the same row $(P<0.05)$. 


\subsection{Changes in Color and 5-HMF}

During storage of fermented litchi juice, a noticeable visual browning was observed, especially in the upper part of the juice bottle (Figure 1), which may be attributed to more oxygen in the top of bottle (Molnar-Perl \& Friedman, 1988; Buedo, Elustondo, \& Urbicain, 2000). Table 2 presented the changes in color parameters of fermented litchi juice during storage. No significant change $(P>0.05)$ for the fermented litchi juice was observed in $L^{*}$ value after 6 months of storage (Table 2), while the $a *, b *$, and $\Delta E$ value for the fermented litchi juice showed a tendency to increase and the $\Delta E$ value reached 5.11 and 7.12 after 3 and 6 months, respectively (Table 2). It can be a noticeable visual difference as the $\Delta E$ value was more than 3.0 (Cao et al., 2012).

Table 2. Change in color for fermented litchi juice during storage

\begin{tabular}{lllll}
\hline Time (months) & $L^{*}$ & $a^{*}$ & $b^{*}$ & $\Delta \mathrm{E}$ \\
\hline 0 & $48.71 \pm 1.32^{\mathrm{a}}$ & $-1.72 \pm 0.32^{\mathrm{c}}$ & $2.05 \pm 0.01^{\mathrm{c}}$ & - \\
3 & $47.68 \pm 1.13^{\mathrm{a}}$ & $-0.96 \pm 0.30^{\mathrm{b}}$ & $6.99 \pm 0.08^{\mathrm{b}}$ & $5.11 \pm 0.11$ \\
6 & $46.31 \pm 1.25^{\mathrm{a}}$ & $-0.59 \pm 0.22^{\mathrm{a}}$ & $8.64 \pm 0.11^{\mathrm{a}}$ & $7.12 \pm 0.04$ \\
\hline
\end{tabular}

a,b,c Different letters represented a significant difference within the same column $(p<0.05)$

Non-enzymatic browning could be a major factor of quality deterioration for the fermented litchi juice showing a noticeable visual browning. It was reported that Maillard reactions are involved in the formation of brown pigments, and 5-HMF is an intermediate product of the maillard reaction (Sapers, 1993; Capuano \& Fogliano, 2011; Lee et al., 2014). Accordingly, the formation of 5-HMF during storage of fermented litchi juice was observed in the study, and the content of 5-HMF increased with the increase of storage times, which reached $2.31 \mathrm{mg} / \mathrm{L}$ after 6 months storage (Table 1 ).

\subsection{Changes in Total Polyphenols and Antioxidant Capacity}

Table 3 presented the changes in total phenolic content, and antioxidant capacity (ORAC value) of fermented litchi juice during storage. The total phenolics content showed a reduction tendency during storage, and which decreased 22\% after 6 months storage. It was reported that total phenolics loss of pasteurized juice during storage was mainly due to the phenolics oxidation degradation and polymerization (between phenolics or phenolics and proteins) (Cao et al., 2011).

No significant decrease $(P>0.05)$ in the ORAC value of fermented litchi juice was observed after 6 months storage, even though the ORAC value in fermented litchi juice showed a 9\% reduction after 6 months storage (Table 3). The major compounds with the oxygen radical absorbance capacity in litchi juice was phenolics, and some studies showedthattotal phenolic contentand the antioxidant capacity were correlated (Mccue \& Shetty, 2005; Klopotek, Otto \& Bohm, 2005; Perez-Gregorio et al, 2011). In this study, the data trends for total phenolic content and antioxidant capacity (ORAC value) during fermented litchi juice storage not showed positively associated (Table 3), which may be due that the products of phenolics oxidation degradation and polymerization also have some antioxidant capacity. Studies showed that antioxidant capacity of phenolics depend on their chemical structure and can be affected by the group attached to a basic aglycon (Jakobek et al., 2009; Perez-Gregorio et al, 2011). Therefore, this could be the subject of further research, because a new antioxidant compound, which exhibits super high antioxidant capacity, much stronger than the capacity of existing antioxidants, may be formed during storage of fermented litchi juice.

Table 3. Changes in total phenolics (mg/L), and antioxidant capacity (ORAC value, $\mathrm{mM} \mathrm{TE/L)} \mathrm{for} \mathrm{fermented}$ litchi juice during storage

\begin{tabular}{llll}
\hline Storage times & 0 day & 3 months & 6 months \\
\hline Total phenolics & $229.78 \pm 4.13^{\mathrm{a}}$ & $194.39 \pm 2.69^{\mathrm{b}}$ & $179.00 \pm 2.49^{\mathrm{c}}$ \\
Antioxidant capacity & $15.26 \pm 0.31^{\mathrm{a}}$ & $15.21 \pm 0.19^{\mathrm{a}}$ & $13.82 \pm 0.29^{\mathrm{b}}$ \\
\hline
\end{tabular}

${ }^{\mathrm{a}, \mathrm{b}, \mathrm{c}}$ Different letters represented a significant difference within the same row $(p<0.05)$

\subsection{Change in Soluble Phenolic Compounds}

There were five soluble phenolic compounds identified in fermented litchi juice by the standards and published data (Zhang et al. 2016), including Rutin, Narcissoside, Quercetin, Kaempferol-rutinose-rhamnoside, and Isorhamnetin-rutinose-rhamnoside. Phenolic compounds comprise an aromatic ring, bearing one or more hydroxyl substituents, and range from simple phenolic molecules to highly polymerized compounds. Phenolic acids, flavonoids and tannins are regarded as the main phenolic compounds in fruits (Rodríguez et al., 2009; 
Aydin \& Mammadov, 2017). Most naturally occurring phenolic compounds are present as conjugates with mono- and polysaccharides, linked to one or more of the phenolic groups, and may also occur as functional derivatives such as esters and methyl esters (Bonoli et al., 2004; Rodríguez et al., 2009). The five soluble phenolic compounds identified in fermented litchi juice is flavonoids, soluble phenolic acids and tannins was not observed and identified. All content of five phenolic compounds identified in fermented litchi juicedid not show significant decrease (Table 4) $(P>0.05)$, whereas total phenolicscontent showed a decrease tendency during storage (Table 3), indicating oxidation degradation or polymerization of some insoluble-bound phenolic compounds could be the main factor that caused the decrease in total phenolics.

Table 4. Change in phenolic compounds for fermented litchi juice during storage

\begin{tabular}{llllll}
\hline Time (months) & $\begin{array}{l}\text { Rutin } \\
(\mathrm{mg} / \mathrm{L})\end{array}$ & $\begin{array}{l}\text { Narcissoside } \\
(\mathrm{mg} / \mathrm{L})\end{array}$ & $\begin{array}{l}\text { Quercetin } \\
(\mathrm{mg} / \mathrm{L})\end{array}$ & $\begin{array}{l}\text { Kaempferol- rutinose - } \\
\text { rhamnoside }(\mathrm{mg} / \mathrm{L})\end{array}$ & $\begin{array}{l}\text { Isorhamnetin - rutinose- } \\
\text { rhamnoside }(\mathrm{mg} / \mathrm{L})\end{array}$ \\
\hline 0 & $10.52 \pm 0.28^{\mathrm{a}}$ & $4.74 \pm 0.7^{\mathrm{a}}$ & $115.31 \pm 4.54^{\mathrm{a}}$ & $16.08 \pm 1.64^{\mathrm{a}}$ & $3.96 \pm 0.48^{\mathrm{a}}$ \\
3 & $10.84 \pm 0.54^{\mathrm{a}}$ & $4.84 \pm 0.64^{\mathrm{a}}$ & $112.7 \pm 3.52^{\mathrm{a}}$ & $14.58 \pm 2.01^{\mathrm{a}}$ & $3.93 \pm 0.33^{\mathrm{a}}$ \\
6 & $9.85 \pm 0.48^{\mathrm{a}}$ & $4.34 \pm 0.47^{\mathrm{a}}$ & $112.6 \pm 3.28^{\mathrm{a}}$ & $14.75 \pm 0.33^{\mathrm{a}}$ & $3.95 \pm 0.51^{\mathrm{a}}$ \\
\hline
\end{tabular}

a,b,c Different letters represented a significant difference within the same column $(p<0.05)$

\subsection{Changes in Free Amino Acids (AA)}

There are 22 kinds of free amino acids that were detected. Most of free AA had no significant changes after 6 months of storage $(P>0.05)$, just 8 kinds of free amino acids (Ser, Glu, Ala,Val, $\gamma$-ABA, Orn, 1Mehis, $\alpha$-AAA) showed a tendency of decrease during storage (Table 5). Silvan et al. reported that some free amino acids was the one of reactants participated in maillard reaction, the results indicated that the loss of some free amino acids may be related to the maillard reaction and the browning of fermentation litchi juices during storage (Azandouz \& Puigserver, 1999; Jiang et al., 2017).

Table 5. Changes in free amino acids $(\mathrm{mg} / \mathrm{L})$ fermented litchi juice during storage

\begin{tabular}{llll}
\hline Time (months) & 0 & 3 & 6 \\
\hline Asp & $137.32 \pm 1.82^{\mathrm{a}}$ & $129.42 \pm 2.06^{\mathrm{a}}$ & $133.48 \pm 1.91^{\mathrm{a}}$ \\
Thr & $17.09 \pm 1.22^{\mathrm{a}}$ & $15.91 \pm 1.43^{\mathrm{a}}$ & $16.34 \pm 0.86^{\mathrm{a}}$ \\
Ser & $76.94 \pm 2.33^{\mathrm{a}}$ & $73.11 \pm 3.96^{\mathrm{a}}$ & $73.95 \pm 2.93^{\mathrm{a}}$ \\
Glu & $62.73 \pm 1.33^{\mathrm{a}}$ & $57.34 \pm 0.96^{\mathrm{b}}$ & $58.22 \pm 1.4^{\mathrm{b}}$ \\
Gly & $16.84 \pm 1.02^{\mathrm{a}}$ & $16.71 \pm 1.48^{\mathrm{a}}$ & $16.49 \pm 1.32^{\mathrm{a}}$ \\
Ala & $559.29 \pm 13.9^{\mathrm{a}}$ & $547.57 \pm 12.6^{\mathrm{a}}$ & $545.25 \pm 19.5^{\mathrm{a}}$ \\
Val & $67.68 \pm 3.56^{\mathrm{a}}$ & $63.05 \pm 3.27^{\mathrm{a}}$ & $64.10 \pm 3.24^{\mathrm{a}}$ \\
Met & $18.56 \pm 2.25^{\mathrm{a}}$ & $17.65 \pm 2.77^{\mathrm{a}}$ & $17.27 \pm 2.38^{\mathrm{a}}$ \\
Cysthi & $12.94 \pm 1.04^{\mathrm{a}}$ & $11.97 \pm 1.69^{\mathrm{a}}$ & $11.98 \pm 1.42^{\mathrm{a}}$ \\
Ile & $15.48 \pm 2.39^{\mathrm{a}}$ & $14.01 \pm 2.46^{\mathrm{a}}$ & $14.48 \pm 2.58^{\mathrm{a}}$ \\
Leu & $5.78 \pm 1.21^{\mathrm{a}}$ & $6.13 \pm 1.18^{\mathrm{a}}$ & $6.29 \pm 1.32^{\mathrm{a}}$ \\
Tyr & $23.61 \pm 2.76^{\mathrm{a}}$ & $23.32 \pm 2.81^{\mathrm{a}}$ & $24.47 \pm 2.54^{\mathrm{a}}$ \\
Phe & $12.92 \pm 1.53^{\mathrm{a}}$ & $11.97 \pm 1.48^{\mathrm{a}}$ & $12.25 \pm 1.29^{\mathrm{a}}$ \\
$\beta-$-Ala & $8.53 \pm 0.48^{\mathrm{a}}$ & $7.59 \pm 0.43^{\mathrm{b}}$ & $6.91 \pm 0.31^{\mathrm{c}}$ \\
$\gamma$-ABA & $831.35 \pm 12.08^{\mathrm{a}}$ & $809.32 \pm 11.64^{\mathrm{b}}$ & $797.95 \pm 9.69^{\mathrm{c}}$ \\
EOHNH2 & $15.75 \pm 0.47^{\mathrm{a}}$ & $15.98 \pm 0.52^{\mathrm{a}}$ & $14.88 \pm 0.59^{\mathrm{a}}$ \\
Orn & $68.26 \pm 0.94^{\mathrm{a}}$ & $61.46 \pm 0.86^{\mathrm{b}}$ & $63.71 \pm 0.72^{\mathrm{b}}$ \\
Lys & $24.33 \pm 1.43^{\mathrm{a}}$ & $21.72 \pm 1.21^{\mathrm{a}}$ & $23.17 \pm 0.99^{\mathrm{a}}$ \\
1Mehis & $30.38 \pm 1.22^{\mathrm{a}}$ & $24.06 \pm 0.98^{\mathrm{b}}$ & $21.10 \pm 1.07^{\mathrm{c}}$ \\
Pro & $24.06 \pm 1.01^{\mathrm{a}}$ & $23.42 \pm 0.98^{\mathrm{a}}$ & $22.68 \pm 1.21^{\mathrm{a}}$ \\
$\alpha$-ABA & $13.35 \pm 1.06^{\mathrm{a}}$ & $13.89 \pm 0.79^{\mathrm{a}}$ & $13.25 \pm 1.03^{\mathrm{a}}$ \\
$\alpha$-AAA & $16.32 \pm 0.71^{\mathrm{a}}$ & $4.69 \pm 0.73^{\mathrm{b}}$ & $\mathrm{N} . \mathrm{D}^{\mathrm{c}}$ \\
\hline
\end{tabular}

${ }^{a, b, c}$ Different letters represented a significant difference within the same row $(p<0.05)$

N.D. Contents below the detection limit. The detection limit of $\alpha$-AAA was $0.05 \mathrm{mg} / \mathrm{L}$.

\subsection{Effect of Adding Sodium Sulfite on Quality Attributes Related to Browning during Storage}

Sulfite is widely used to prevent browning reactions of fruit juices (Zhou, Zhang \& Xin, 2004; Wu, 2014). In this 
study, thequality attributes related to browning was also analyzed for the fermented litchi juice added with 0.3 $\mathrm{g} / \mathrm{L}$ of sodium sulfite. Compared with fermented litchi juice not added with sodium sulfite, the $\Delta E$ value showed a slower increase and less than 3.0 (Figure $2 \mathrm{~A}$ ), and noticeable visual browning was not observed in the fermented litchi juice added with $0.3 \mathrm{~g} / \mathrm{L}$ of sodium sulfite during storage of 6 months (Figure 1). Moreover, the increase of 5-HMF and loss of total phenolics was less in the fermented litchi juice added with $0.3 \mathrm{~g} / \mathrm{L}$ of sodium sulfite as compared with fermented litchi juice not added with sodium sulfite during storage of 6 months (Figure 2B and 2C). No significant different $(P>0.05)$ was observed in TSS, $\mathrm{pH}$, titratable acidity, sugar, soluble phenolic compounds, and free amino acids after 3 or 6 months of storage (data not presented).

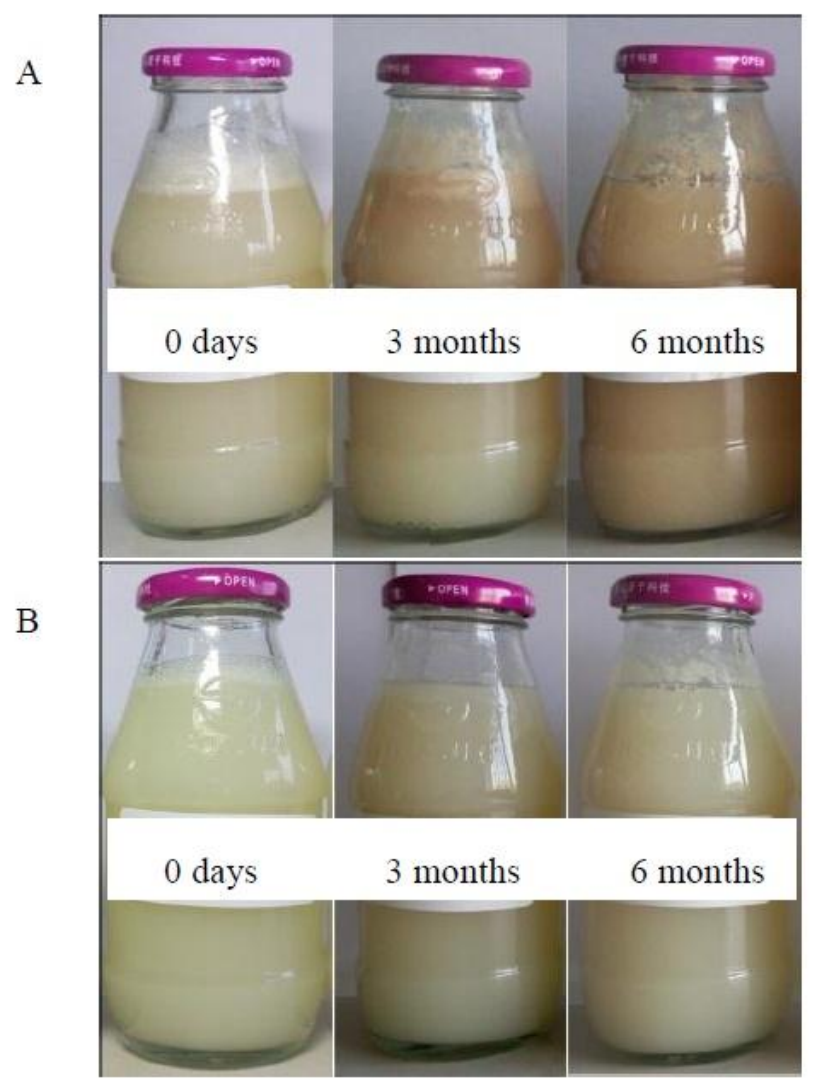

Figure 1. Change in color for fermented litchi juice adding without (A) or with (B) $0.3 \mathrm{~g} / \mathrm{L}$ of sodium sulfite during storage

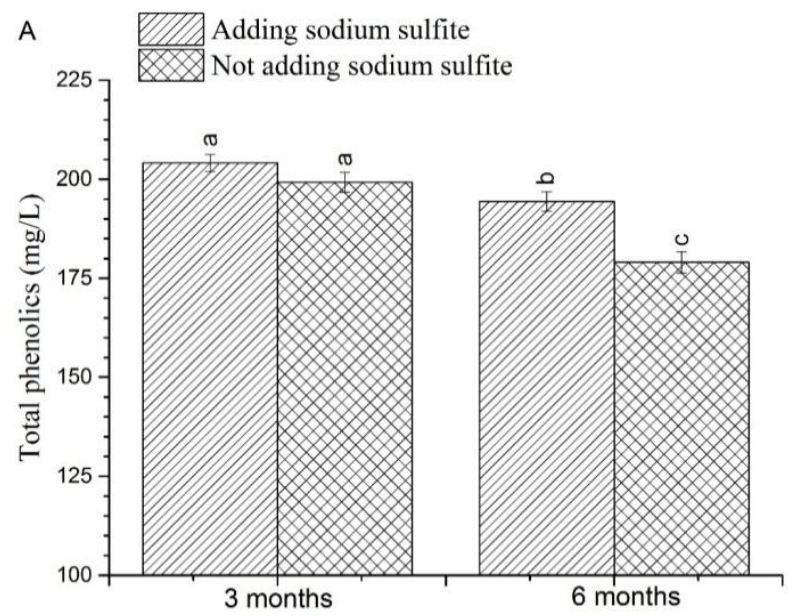


B

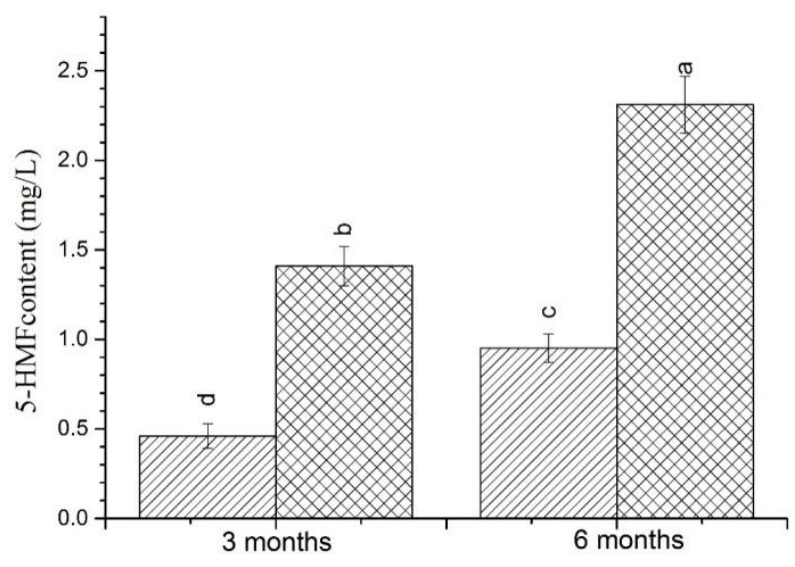

C

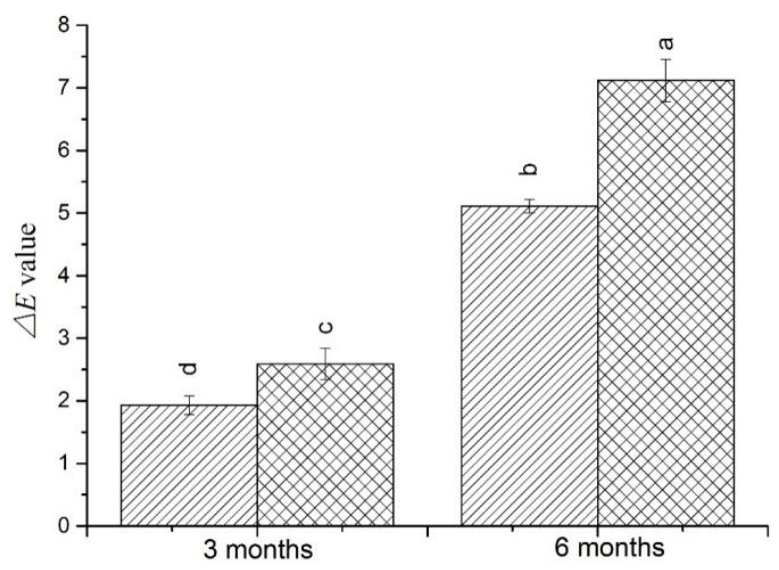

Figure 2. Change in total phenolics (A), 5-HMF (B)and $\Delta E$ value (C) for fermented litchi juice adding without or with $0.3 \mathrm{~g} / \mathrm{L}$ of sodium sulfite during storage.

\section{Conclusion}

Pasteurized ( $95^{\circ} \mathrm{C}, 1 \mathrm{~min}$ ) fermented litchi juice with Lactobacillus casei showed a noticeable visual browning during storage at $25^{\circ} \mathrm{C}$, especially in the upper part of the juice bottle. The non-enzymatic browning is the major quality deterioration during storage of fermented litchi juice, which are related to ascorbic acid (AA) degradation, Maillard-associated reactions, intermediates of AA and sugar degradation, and so on. It was found that sodium sulfite can decrease the formation of 5-HMF and the loss of total phenolics, and inhibited browning reaction of fermented litchi juice. Analysis of quality attributes related to browning during storage showed sodium sulfite or other similar anti-browning agent should be using to inhibit the formation of 5-HMF and the loss of total phenolics, and decrease the browning of fermented litchi juice.

\section{Acknowledgement}

This research was supported by Project No. 2017YFD0400703 of National key research and development project, Project No. 2015A030312001 of Natural Science Foundation of Guangdong Province, and Project No. 201704020037and 201803020007 of Guangzhou Science and Technology Project, China.

\section{Author Contributions}

Yuanshan Yu, Xinxin Yuan and Yujuan Xu designed the experiments, analyzed the data and reviewed the manuscript; Gengsheng Xiao and Jijun $\mathrm{Wu}$ collected the data and wrote the manuscript. All of the authors completed and authorized the definitive manuscript.

\section{References}

Aydin, C., \& Mammadov, R. (2017). Phenolic composition, antioxidant, antibacterial, larvacidal against Culex 
pipiens, and cytotoxic activities of Hyacinthellalineatasteudel extracts. International Journal of Food Properties, 20(10), 2276-2285. https://doi.org/10.1080/10942912.2016.1236271

Azandouz, E. H., \& Puigserver, A. (1999). Non enzymatic browning reaction of essential amino acids:Effect of $\mathrm{pH}$ on caramelization and Maillard reactions kinetics. Journal of Agricultural and Food Chemistry, 47(5), 1786-1793. https://doi.org/10.1021/jf980928z

Bonoli, M., Marconi, E., \& Caboni, M. F. (2004). Free and bound phenolic compounds in barley (Hordeum vulgare L.) flours: Evaluation of the extraction capability of different solvent mixtures and pressurized liquid methods by micellar electrokinetic chromatography and spectrophotometry. Journal of Chromatography A., 1057, 1-12. https://doi.org/10.1021/jf040075c

Borneman, Z., Kmen, V. G., \& Nijhuis, H. H. (2001). Selective removal of polyphenols and brown color in apple juices using PES/PVP membranes in a single ultrafiltration process. Separation and Purification Technology, 22, 53-61. https://doi.org/10.1021/jf803961f

Buedo,A. P., Elustondo, M. P., \& Urbicain, M. J. (2000). Non-enzymatic browning of peach juice concentrates during storage. Innovative Food Science \& Emerging Technologies, 1, 255-260. https://doi.org/10.1016/S1466-8564(00)00031-X

Cao, X., Bi, X., Huang, W., Wu, J., Hu, X., \& Liao, X. (2012). Changes of quality of high hydrostatic pressure processed cloudy and clear strawberry juices during storage. Innovative Food Science \& Emerging Technologies, 16, 181-90. https://doi.org/10.1016/j.ifset.2012.05.008

Cao, X., Zhang, Y., Zhang, F., Wang, Y., Yi, J., \& Liao, X. (2011). Effects of high hydrostatic pressure on enzymes, phenolic compounds, anthocyanins, polymeric color and color of strawberry pulps. Journal of Agricultural and Food Chemistry, 91, 877-85. https://doi.org/10.1002/jsfa.4260

Capuano, E., \& Fogliano, V. (2011). Acrylamide and 5-hydroxymethylfurfural (HMF): A review on metabolism, toxicity, occurrence in food and mitigation strategies. LWT - Food Science and Technology, 44(4), 793-810. https://doi.org/10.1016/j.lwt.2010.11.002

Chaikham, P., Rattanasena, P., Phunchaisri, C., \& Sudsanora, P. (2017). Quality changes of litchi (LitchichinensisSonn.) in syrup due to thermal and high pressure processes. LWT - Food Science and Technology, 75, 751-760. https://doi.org/10.1016/j.lwt.2016.10.037

Damasceno, L. F., Fernandes, F. A.N., Magalhães, M. M. A., \& Brito, E. S. (2018). Non-enzymatic browning in clarified cashew apple juice during thermal treatment: Kinetics and process control, Food Chemistry, 106, 172-179. https://doi.org/10.1016/j.foodchem.2007.05.063

Fustier, P., St-Germain, F., Lamarche, F., \& Mondor M. (2011). Non-enzymatic browning and ascorbic acid degradation of orange juice subjected to electroreduction and electro-oxidation treatments. Innovative Food Science \& Emerging Technologies, 12(4), 491-498. https://doi.org/10.1016/j.ifset.2011.07.014

Gan, R. Y., Shah, N. P., Wang, M. F., Lui, W. Y., \& Corke, H. (2016). Lactobacillus plantarum WCFS1 fermentation differentially affects antioxidant capacity and polyphenol content in mung bean (Vigna radiata) and soya bean (Glycine max) milks. Journal of Food processing and Preservation, 41, 12944-12949. https://doi.org/10.1111/jfpp.12944

Hernández E, Raventós M, Auleda J M, \& Ibarz, A. (2009). Concentration of apple and pear juices in a multi-plate freeze concentrator. Innovative Food Science \& Emerging Technologies, 10(3), 348-355. https://doi.org/10.1016/j.ifset.2009.02.001

Holcroft, D. M., \& Mitcham, E. J. (1996). Postharvest physiology and handling of litchi (Litchi chinensisSonn.). Postharvest Biology and Technology, 9(3), 265-281. https://doi.org/10.1016/S0925-5214(96)00037-3

Ibarz, A., Pagán, J., \& Garza, S. (1999). Kinetic models for colour changes in pear puree during heating at relatively high temperatures. Journal of Food Engineering, 39(4), 415-422. https://doi.org/10.1016/S0260-8774(99)00032-1

Ibegbulem, C. O., Igwe, C. U., Okwu, G. N., Ujowundu, C. O., Onyeike, E. N., \& Ayalogu, E. O. (2013). Total amino acid profiles of heat-processed fresh Elaeisguineensis and Raphia hookeri wines. Food Chemistry, 138, 1616-1620. https://doi.org/10.1016/j.foodchem.2012.11.110

Ibrahim, S. R. M., \& Mohamed, G. A. (2015). Litchi chinensis: medicinal uses, phytochemistry, and pharmacology. Journal of Ethnopharmacology, 174, 492-513. https://doi.org/10.1016/j.jep.2015.08.054

Jakobek, L., Seruga, B., Novak, I., \& Medvidovic-Kosanovic, M. (2009). Phenolic compound composition and 
antioxidant activity of fruits of Rubus and Prunus species from Croatia. International Journal of Food Science and Technology, 44, 860-868. https://doi.org/10.1111/j.1365-2621.2009.01920.x

Jiang, W., He, X., Yang, H., Xiang, X., Hu, S., Li, S., \& Liu, Y. (2017). Histamine reduction by Maillard reaction with glucose. Food Control, 82,136-144. https://doi.org/10.1016/j.foodcont.2017.06.035

Kabasakalis, V., Siopidou, D., \& Moshatou, E. (2000). Ascorbic acid content of commercial fruit juices and its rate of loss upon storage. Food Chemistry, 70, 325-328. https://doi.org/10.1016/S0308-8146(00)00093-5

Kennedy, J. F., Rivera, Z. S., Lloyd, L. L., Warner, F. P., \& Jumel, K. (1992). L-Ascorbic acid stability in aseptically processed orange juice in TetraBrik cartons and the effect of oxygen. Food Chemistry, 45, 327-31. https://doi.org/10.1016/0308-8146(92)90032-W

Klopotek, Y., Otto, K., \& Bohm, V. (2005). Processing strawberries to different products alters contents of vitamin $\mathrm{C}$, total phenolics, total anthocyanins and antioxidant capacity. Journal of Agricultural and Food Chemistry, 53, 5640-5646. https://doi.org/10.1021/jf047947v

Lee, T. P., Sakai, R., Manaf, N. A., Rodh, A. M., \& Saas, B. (2014). High performance liquid chromatography method for the determination of patulin and 5-hydroxymethylfurfural in fruit juices marketed in Malaysia. Food Control, 38, 142-149.https://doi.org/10.1016/j.foodcont.2013.10.018

Mccue, P. P., \& Shetty, K. (2005). Phenolic antioxidant mobilization during yogurt production from soymilk using Kefir cultures. Process Biochemistry, 40, 1791-1797. https://doi.org/10.1016/j.procbio.2004.06.067

Molnar-Perl, I., \& Friedman, M. (1998). Inhibition of browning by sulfur amino acids. 2.Fruit juices and protein containing foods. Journal of Agricultural and Food Chemistry, 38, 1648-1651. https://doi.org/10.1021/jf00098a005

Ou, B., Hampsch-Woodill, M., \& Prior, R. L. (2001). Development and validation of an improved oxygen radical absorbance capacity assay using fluorescein as the fluorescent probe. Journal of Agricultural and Food Chemistry, 49, 4619-4626. https://doi.org/10.1021/jf010586o

Perez-Gregorio, M. R., Regueiro, J., Alonso-Gonzalez, E., Pastrana-Castro, L. M., \& Simal-Gandara, J. (2011). Influence of alcoholic fermentation process on antioxidant activity and phenolic levels from mulberries (Morusnigra L.). LWT- Food Science and Technology, 44, 1793-801. https://doi.org/10.1016/j.lwt.2011.03.007

Quayson, E. T., \& Ayernor G. S. (2007). Non-enzymatic browning and estimated acrylamide in roots, tubers and plantain products. Food Chemistry, 105, 1525-1529. https://doi.org/10.1016/j.foodchem.2007.05.066

Rodríguez, H., Curiel, J. A., Landete, J. M., De Las Rivas, B., De Felipe F. L., Gómez-Cordovés, C., Mancheño, J. M., \& Muñoz, R. (2009). Food phenolics and lactic acid bacteria. International Journal of Food Microbiology, 132, 79-90. https://doi.org/10.1016/j.ijfoodmicro.2009.03.025

Sapers, G. M. (1993). Browning of foods: Control by sulfites, antioxidants and other means. Food Technology, 47(10), 75-84.

Silván, J. M., van de Lagemaat, J., Olano, A., \& del Castillo, M. D. (2006). Analysis and biological properties of amino acid derivates formed by Maillard reaction in foods[J]. Journal of Pharmaceutical and Biomedical Analysis, 41(5), 1543-1551. https://doi.org/10.1016/j.jpba.2006.04.004

Wu, M., Hu, Z. Y., \& Zheng, P. (2013). Effect of packaging material on the non-Enzymatic browning of litchi juice. Applied Mechanics and Materials, 312, 337-340. https://doi.org/10.4028/www.scientific.net/AMM.312.337

$\mathrm{Wu}$, S. (2014). Glutathione suppresses the enzymatic and non-enzymatic browning in grape juice. Food Chemistry, 160, 8-10. https://doi.org/10.1016/j.foodchem.2014.03.088

Yang, J., Zhang, X., Jin, Q., Gu, L., Liu, X., Li, J., \& Ni, Y. (2017). Effect of meteorological parameters and regions on accumulation pattern of phenolic compounds in different mulberry cultivars grown in China. Natural Product Research, 31, 1091-1096. https://doi.org/10.1080/14786419.2016.1274895

Yu Y., Xu, Y., Wu J., Xiao G., Fu, M., \& Zhang, Y. (2014). Effect of ultra-high pressure homogenisation processing on phenolic compounds, antioxidant capacity and anti-glucosidase of mulberry juice. Food Chemistry, 153, 114-120. https://doi.org/10.1016/j.foodchem.2013.12.038

Yu, Y., Xiao, G., Xu, Y., Wu, j., Fu, M., \& Wen, J. (2015). Slight fermentation with Lactobacillus fermentium improves the taste (Sugar:Acid Ratio) of Citrus (Citrus reticulata cv. chachiensis) juice. Journal of Food 
Science, 80(11), M2543-47. https://doi.10.1111/1750-3841.13088

Zhang R, Zeng Q, Deng Y, Zhang, M., Wei, Z., Zhang, Y., \& Tang, X. (2016). Phenolic profiles and antioxidant activity of litchi pulp of different cultivars cultivated in Southern China. Food Chemistry, 136, 1169-1176. https://doi.org/10.1016/j.foodchem.2012.09.085

Zheng, X., Yu, Y., Xiao, G., Xu, Y., Wu, J., Tang, D., \& Zhang, Y. (2014). Comparing product stability of probiotic beverages using litchi juice treated by high hydrostatic pressure and heat as substrates. Innovative Food Science and Emerging Technologies, 23, 61-67. https://doi.org/10.1016/j.ifset.2014.01.013

Zhou, D. Q., Zhang, S. L., \& Xin, S. C (2004). Review on the Function and Application of Sulphite in Food Processing. Shi Pin KeXue (China), 25, 198-201.

\section{Copyrights}

Copyright for this article is retained by the author(s), with first publication rights granted to the journal.

This is an open-access article distributed under the terms and conditions of the Creative Commons Attribution license (http://creativecommons.org/licenses/by/4.0/). 